\title{
Review
}

\section{Diabetic dyslipidaemia: from basic research to clinical practice*}

\author{
M.-R. Taskinen \\ Department of Medicine, Division of Cardiology, University of Helsinki, Helsinki, Finland
}

\section{Abstract}

The recognition that the increase of plasma triglyceride rich lipoproteins (TRLs) is associated with multiple alterations of other lipoproteins species that are potentially atherogenic has expanded the picture of diabetic dyslipidaemia. The discovery of heterogeneity within major lipoprotein classes VLDL, LDL and HDL opened new avenues to reveal the specific pertubations of diabetic dyslipidaemia. The increase of large VLDL 1 particles in Type 2 diabetes initiates a sequence of events that generates atherogenic remnants, small dense LDL and small dense HDL particles. Together these components comprise the atherogenic lipid triad. Notably the malignant nature of diabetic dyslipidaemia is not completely shown by the lipid measures used in clinical practice. The key question is what are the mechanisms behind the increase of VLDL 1 particles in diabetic dyslipidaemia? Despite the advances of recent years, our understanding of VLDL assembly and secretion is still surprisingly incomplete. To date it is still unclear how the liver is able to regulate the amount of triglycerides incorpo- rated into VLDL particles to produce either VLDL 1 or VLDL 2 particles. The current evidence suggests that the machinery driving VLDL assembly in the liver includes (i) low insulin signalling via PI-3 kinase pathway that enhances lipid accumulation into "nascent" VLDL particles (ii) up-regulation of SREBP-1C that stimulates de novo lipogenesis and (iii) excess availability of "polar molecules" in hepatocytes that stabilizes apo B 100. Recent data suggest that all these steps could be fundamentally altered in Type 2 diabetes explaining the overproduction of VLDL apo B as well as the ability of insulin to suppress VLDL 1 apo B production in Type 2 diabetes.

Recent discoveries have established the transcription factors including PPARs, SREBP-1 and LXRs as the key regulators of lipid assembly in the liver. These observations suggest these factors as a new target to tailor more efficient drugs to treat diabetic dyslipidaemia. [Diabetologia (2003) 46:733-749]

Keywords Lipids, apoliproteins, insulin, Type 2 diabetes, liver fat, coronary heart disease, stable isotopes, transcription factors
Received: 11 February 2003 / Revised: 11 April 2003

Published online: 28 May 2003

(C) Springer-Verlag 2003

Corresponding author: Dr. M.-R. Taskinen, Department of Medicine, Division of Cardiology, University of Helsinki, Helsinki, Finland

E-mail: mataskin@helsinki.fi

Abbreviations: ABCA-1, ATP cassette binding protein-1; ARF-1, ADP ribosylation factor 1; ATP III, Adult Treatment Panel III; CE, cholesterylester; CETP, cholesterylester transfer protein; CVD, cardiovascular disease; DAIS, Diabetes Atherosclerosis Intervention Study; DNL, de novo lipogenesis; GGE, gradient gel electrophoresis; HL, hepatic lipase; HPS, Heart Protection
Study; HSPG, heparinsulfate proteoglycan; IDL, intermediate density lipoprotein; LPL, lipoprotein lipase; LRP, the LDL receptor-related protein; LXR, liver X-receptor; MI, myocardial infarction; MTP, microsomal transfer protein; PI-3 kinase, phospohotidylinositol 3 kinase; PLD, phospholipase D; PLTP, phospholipid transfer protein; PPAR, peroxisome proliferator-activator receptor; Sf, Svedberg flotation rate; SREBP, sterol regulatory element-binding protein; SR-BI, scavenger receptor BI; $\mathrm{Tg}$, triglycerides; TRL, triglyceride rich lipoproteins; TZD, thiazolidineodione; VA-HIT, Veterans Affairs HDL Intervention Study.

* The $38^{\text {th }}$ Claude Bernard Lecture of European Association for the Study of Diabetes 
In Type 2 diabetes dyslipidaemia is an important and common risk factor for coronary heart disease (CHD) that is the leading cause of morbidity and mortality worldwide [1, 2]. The International Diabetes Federation (IDF) foresees a rise of epidemic proportions in Type 2 diabetes that portends a daunting increase in CHD [3]. Solid evidence has confirmed that people with Type 2 diabetes have a similar risk of heart attack as people without diabetes who have already had a heart attack $[4,5]$. Adult Treatment panel III (ATP III) designated diabetes as a CHD risk equivalent and LDL was identified the first priority of lipid lowering [6].

Recent developments have recognized the complex nature of diabetic dyslipidaemia that is a cluster of potentially atherogenic lipid and lipoprotein abnormalities [7]. Two core components of diabetic dyslipidaemia are increased plasma triglycerides and low concentrations of HDL cholesterol. More recently recognized features are small dense LDL and excessive postprandial lipemia. These components are not isolated abnormalities but metabolically closely linked to each other. The aim of this review is to build up a concept that recognizes the heterogeneity of lipoprotein classes and the co-ordinated regulation of different lipoprotein species and specifies the perturbations associated with Type 2 diabetes. A better understanding of the pathophysiology behind diabetic dyslipidaemia will allow us to tailor targeted goals for the lipid management.

\section{Heterogeneity of triglyceride rich lipoproteins (TRLs)}

\section{Distribution of TRL species}

Plasma TRLs are a mixture of lipoprotein species characterized by the different density and apoprotein composition, derived either from intestine (chylomicrons) or the liver (VLDL) (Fig. 1) [8, 9]. In chylomicrons the major structural protein is apo B 48 which is synthesized only in the enterocytes. The major protein of VLDL particles is apolipoprotein B 100, produced by the liver. The specific determination of apo B 48 and apo B 100 by polyacrylamide-agarose gradient gel electrophoresis (GGE) allows the separation of particles from endogenous and exogenous origin sharing the same density.

The size of endogenous VLDL particles varies markedly from about $350 \AA$ to $700 \AA$ in diameter [10]. Most of this difference is due to variation in the amount of triglycerides in the core. The common way to isolate the VLDL subfractions is by density gradient ultracentrifugation. Endogenous VLDL particles can be separated into two main subclasses: large buoyant VLDL 1 particles (Sf $60-400$ ) and smaller and more dense VLDL 2 particles (Sf 20-60). VLDL
Metabolism of TRLs

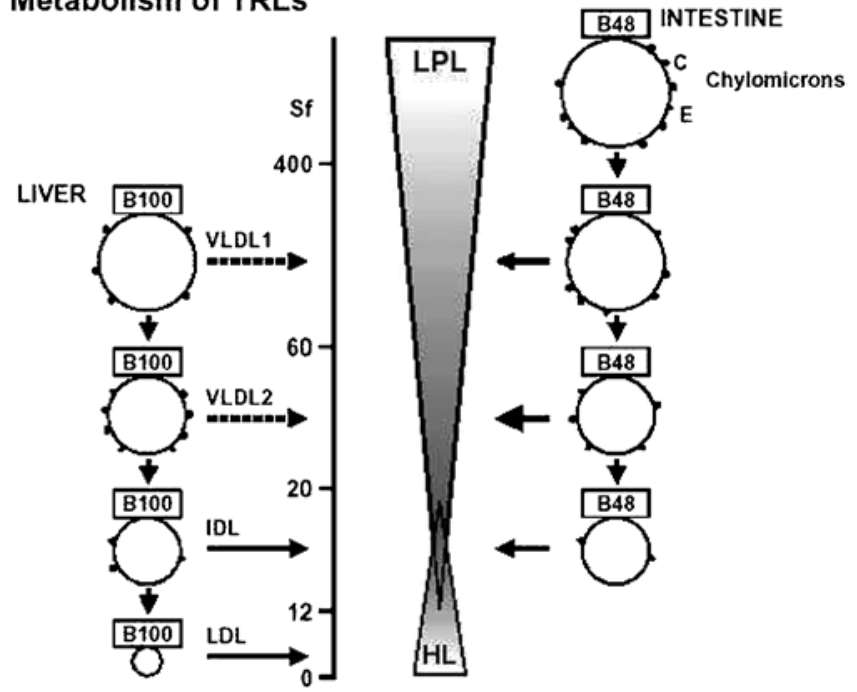

Fig. 1. Portrayed here is the metabolic scheme for delipidation cascade of TRL particles derived from liver (VLDL) and intestine (chylomicrons). Independently of the origin, TRL particles reside within the same flotation rates $(\mathrm{Sf})$. Both chylomicrons and VLDL particles share the same catabolic pathways that begin with hydrolysis first by lipoprotein lipase and then by hepatic lipase. Chylomicrons and VLDL particles cannot be separated by density (Sf flotation rate) because both particles reside in the same density ranges (VLDL 1 Sf 60-400; VLDL 2 Sf 20-60). The determination of apo B 100 and apo B 48 allows separation of particles from endogenous and exogeneous origins. Reproduced from reference [8] with permission of Exp Clin Endocrinol Diabetes (Exp Clin Endocrinol Diabetes 2001;109:173-181. Georg Thieme Verlag)

subclasses show distinct differences in the size, composition and metabolic function. Both endogenous and exogenous TRL particles are processed via the same delipidation cascade. The lipolytic rate of TRLs is regulated by two enzymes: lipoprotein lipase (LPL) and hepatic lipase (HL), as well as by the composition of TRL particles. The first step in the clearance of TRLs is the hydrolysis of lipoprotein triglycerides by LPL. A number of studies have reported that LPL activity is frequently low or subnormal in subjects with Type 2 diabetes [11]. In the second step of the hydrolytic process hepatic lipase is responsible for the conversion of IDL particles into LDL particles. Substantial evidence indicates that hepatic lipase activity is commonly increased in Type 2 diabetes and this can enhance the conversion of IDL into LDL [12, 13, 14].

An important observation is that in a population survey of normolipidaemic subjects $75 \%$ of the variation in plasma triglycerides seems to be determined by the VLDL 1 concentration [15]. So far very little attention has been paid to VLDL subclass distribution in diabetes although the increase of plasma triglycerides is a consistent feature of diabetic dyslipidaemia. Recently it was reported [16] that Type 2 diabetic patients had more larger lipid rich VLDL particles than non-diabetic control subjects. We observed a propor- 
tionally higher increase of VLDL 1 particles compared with VLDL 2 particles in a small group of Type 2 diabetic patients [17]. Likewise another study [18] reported a relatively higher increase of VLDL 1 than that of VLDL 2 particles in a small cohort of Type 2 diabetic subjects. Therefore we asked the question whether the increase of VLDL 1 is the key determinant of plasma triglycerides in diabetic dyslipidaemia and what would be the consequences with respect to the metabolism of other lipoproteins? We separated VLDL 1 and VLDL 2 fractions using the density gradient ultracentrifugation from a cohort of 229 Type 2 diabetic patients recruited for the FIELD study in Helsinki [19] as well as from a cohort of non-diabetic subjects matched for age and sex $(n=74)$. The concentration of VLDL 1 triglycerides was higher in Type 2 diabetic subjects than in non-diabetic subjects (mean $\pm \mathrm{SD} ; 0.80 \pm 0.55$ vs $0.34 \pm 0.24 \mathrm{mg} / \mathrm{dl}, p<0.001)$. The respective numbers for VLDL 2 triglycerides were $0.33 \pm 0.16$ and $0.17 \pm 0.08 \mathrm{mg} / \mathrm{dl}(p<0.001)$. Notably the relative increase of triglycerides was 2.3 -fold in VLDL 1 but 1.8-fold in VLDL 2. Altogether these observations suggest that in Type 2 diabetic subjects the increase of VLDL 1 particles contributes more than that of VLDL 2 particles to the increase of TRLs in the fasting state.

\section{Alteration of apoproteins in TRLs}

In addition to apo $\mathrm{B} 100, \mathrm{C}$ and $\mathrm{E}$ apoproteins are important constituents of VLDL particles. Apo C III, which is synthesized mainly in the liver, is the most abundant apolipoprotein in VLDL particles. Apo C III modulates the metabolism of VLDL particles at different steps $[9,20]$. Firstly, apo C III is a direct inhibitor of LPL activity [21]. In the subsequent step apo C III interferes with the apo E-mediated receptor binding, impairing the hepatic uptake of remnants [22, 23]. Plasma apo C-III concentrations are increased in hypertriglyceridaemic subjects and there seems to be a correlation between plasma apo C III and plasma Tg concentrations [20, 24]. Of interest, apo CIII containing TRLs represent most triglyceride-rich species that are catabolized slowly [25, 26]. Emerging evidence suggest that apo CIII containing apo B particles are a better discriminator for CHD risk than particles without apo C III [27, 28]. Plasma triglycerides, apo CIII and apo CIII /B particles were independent markers of cardiovascular disease in a cross-sectional cohort including 188 Type 2 diabetic patients [29]. Unfortunately this study did not include a non-diabetic cohort to allow a comparison. Surprisingly the data on plasma apo CIII in Type 2 diabetes is scarce and inconsistent $[24,30,31,32]$.

The surface of VLDL particles carries both apo E and C III [9]. Apo E has a critical role in the removal process of TRL remnants as the ligand for the LDL re- ceptor-related protein (LRP) and the LDL receptor and by interacting with proteoglycans [33]. Although the importance of apo $\mathrm{E}$ in the remnant removal is well established, the data on apo $\mathrm{E}$ in diabetic dyslipidaemia is incomplete. Our preliminary data suggested that in Type 2 diabetic subjects, postprandial TRLs were rich in apo E [34]. The observation that apo E enrichment of VLDL reduces the catabolic rate of particles represents a paradox, and in contrast suggests that apo E enrichment could aggravate postprandial lipemia. In a recent study, apo $\mathrm{E}$ content of fasting TRL, expressed as a molar ratio of apo E to apo B, was similar in Type 2 diabetic subjects and in control subjects matched for age [35]. Likewise there was no difference between the two groups in the binding of isolated TRLs to both purified biglycan and to the LDL receptor in vitro. Regardless of the lack of information on the apoprotein distribution in TRL subclasses, it is obvious that the apo CIII to apo E ratio can be critical for the metabolic fate of these lipoproteins in diabetic dyslipidaemia as well as for determining their atherogeneity.

\section{Pathophysiology of VLDL metabolism in Type 2 diabetes}

\section{Regulatory steps in VLDL metabolism}

The metabolism of TRLs has several distinct steps that include (i) the assembly and secretion of VLDL particles, (ii) the hydrolysis of triglycerides in TRLs by LPL, (iii) the direct uptake of TRL remnants in the liver, and (iv) the flux of apo B 100 through VLDLIDL-LDL delipidation cascade in circulation. Most of the data on VLDL assembly and secretion has been derived from in vitro cell cultures or from animal experiments $[36,37]$. Insulin has been shown acutely to inhibit the assembly and secretion of VLDL particles by mechanisms involving an increase of apo B degradation and a decrease of the expression of microsomal transfer protein (MTP) in hepatocytes [38, 39]. In contrast, hepatic expression of MTP is increased in the obese and hypertriglyceridaemic rat [40] and in obese diabetic mice [41]. Recent studies using the fructosefed Golden Hamster, an animal model of insulin resistance and dyslipidaemia, have shown that increased expression of MTP and increased lipid availability in the liver is associated with reduced degradation of apo $\mathrm{B}$ and are the forces that are driving the overproduction of apo B in the insulin-resistant state [42, 43].

Do we have tools to explore the complex regulation of VLDL production in humans? The use of stable isotopes provides a method to follow up both the synthesis and secretion of lipoprotein particles from the liver as well as their metabolic fate in circulation [44]. The use of stable isotope leucine allows us to trace apoprotein B100 and the concomitant injection of 


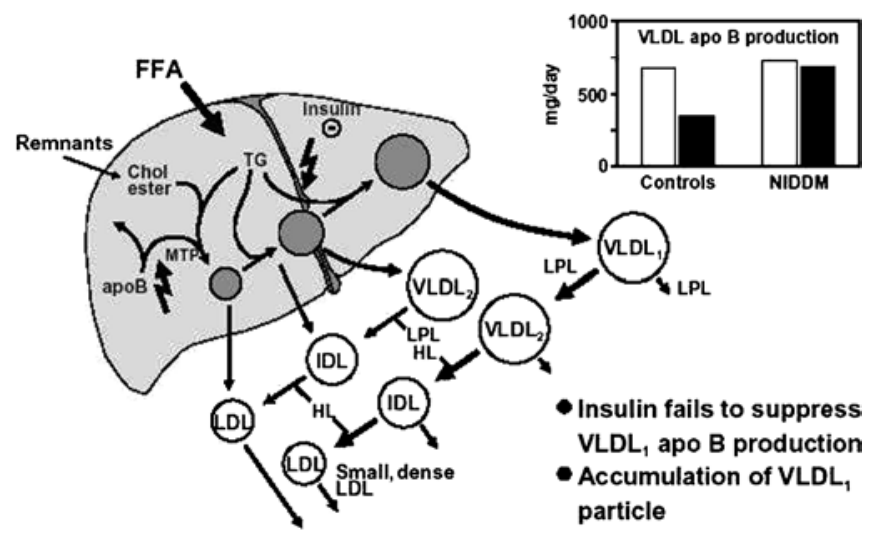

Fig. 2. Portrayed is the metabolic model for apo B metabolism. The lipoprotein assembly is initiated by the lipidation of apo B mediated by MTP. Further lipids are added to the "pre" VLDL particles during its maturation first to VLDL 2 particles and finally to lipid-rich VLDL 2 particle. Apo B-containing particles released into circulation range from LDL to VLDL 1. The loading of newly formed particles with lipids determines the density of secreted particles. The production of VLDL 1 and VLDL 2 particles are regulated independently. The site of insulin action is located at the final step of lipid loading that produces VLDL 1 particles. The particles are subject to lipolysis and remodelling in the circulation and they are metabolized via two parallel cascades. The subscript shows the VLDL apo B production during saline infusion (open columns) and during an 8.5-h euglycaemic clamp (closed columns) in normal healthy men and in Type 2 diabetic subjects. Insulin suppressed the rate of VLDL 1 apo B synthesis by $50 \%$ in normal men but failed to suppress the synthesis of VLDL 1 apo B in Type 2 diabetic men. [Reproduced from references [47, 50] with permission of Diabetologia (Diabetologia 1997; 40:454-462) and Arteriosclerosis Thrombosis Vascular Biology (Arterioscler Thromb Vasc Biol 1997; 17:1454-1464)]

glycerol to label triglycerides. The simultaneous use of these dual traces gives the advantage of endogenous labelling of both VLDL components in the liver. It is well established that the liver secretes a wide spectrum of apo B containing VLDL particles which vary in size and density [10]. The current concept is that the main species of VLDL entering the circulation, namely VLDL 1 and VLDL 2 particles, are secreted into separate metabolic channels within the VLDL-IDL-LDL cascade (Fig. 2). The metabolic processing of VLDL 1 and VLDL 2 species occurs in parallel but have diverse pathways that produce IDL and LDL particles. The recognition that the properties of LDL particles depend closely on its pedigree links the heterogenity of LDL subclasses to the ancestry of VLDL species $[10,45,46]$. Since large VLDL 1 particles are a dominant feature of diabetic dyslipidaemia, we asked whether the channeling of VLDL 1 and VLDL 2 particles is regulated by insulin? We have recently established that in normal healthy men, acute insulin infusion (by using a euglycaemic clamp over $8 \mathrm{~h}$ ) suppressed VLDL 1 apo B production on average by $50 \%$ but had no effect on de novo VLDL 2 apo B production (Fig. 2) [47]. Thus insulin seems to inhibit the production of large buoyant VLDL 1 particles. Likewise the overall production rate of VLDL apo B was reduced by insulin as reported also by others [48]. The divergent action of insulin infusion on large compared with small VLDL particles was confirmed [49]. We envisage large VLDL 1 particles as "liverderived" chylomicrons that should be released only in the fasting state but not in the postprandial phase in the presence of chylomicron flux from the intestine. We propose that one physiological action of insulin is to preserve the balance between intestinally-derived and liver-derived TRL in response to excursions of energy shifts.

In subsequent studies we showed that in Type 2 diabetic men insulin failed to suppress VLDL 1 apo B production during acute hyperinsulinaemia [50]. Thus this new action of insulin was defective in Type 2 diabetic subjects in contrast to normal subjects. This failure of insulin to suppress VLDL 1 particle release in Type 2 diabetes results in inappropriate production of VLDL 1 particles in the postprandial phase when these particles are not needed in the presence of chylomicron flux. The overproduction of VLDL 1 particles can saturate the metabolic capacity and contribute to postprandial lipemia. We speculate that this perturbation is the major cause for the increase of plasma triglyceride concentrations in Type 2 diabetes.

Pertubations in the assembly and secretion of VLDL particles

To date it is still unclear how liver is able to regulate the amount of triglycerides incorporated into VLDL particles to produce predominantly either large VLDL 1 particles versus VLDL 2 particles. The current evidence suggests that factors modulating VLDL assembly and secretion in the liver are (i) expression of MTP, (ii) activation of phosphatidylinositol 3 kinase (PI 3-kinase), (iii) ADP-ribosylation factor (ARF-1) by activating phospholipase D (PLD), and (iv) availability of lipids in hepatocytes. The latter component is closely linked to the influx of NEFA into the liver as well as to de novo lipogenesis (DNL).

The current concept is that the assembly of VLDL particles in the liver involves two distinct steps [51, $52,53]$. The first step of the secretory pathway produces "pre-VLDL" particles that involves the cotranslational lipidation of apo B catalysed by the microsomal triglyceride transfer protein (MTP). This step takes place in the rough endoplasmic reticulum (ER). In the second step the major amount of lipids is incorporated into the core of "pre-VLDL" particles that are transformed into larger VLDL particles. The second step and the transport of VLDL particles into the smooth membrane compartment is driven by ADP ribosylation factor-1 (ARF-1) that regulates VLDL assembly by activating phospholipase D (PLD) [52]. 
The activation of PLD by ARF-1 is linked to intracellular insulin signalling. In this scenario the activated PI 3 kinase converts PI-4,5 biphosphate (PIP2) into PI-3,4,5 triphosphate. Lack of PIP2 prevents the activation of PLD that is necessary for the formation of lipid droplets and the actual assembly of lipids into "pre-VLDL" [52]. The normal inhibitory effect of insulin on VLDL assembly is located at the second step and linked to the lack of PLD activation during normal intracellular insulin signalling. In contrast a defective activation of PI-3 kinase in insulin resistant state results in an excess of PI-4,5-biphosphate that in turn signals the activation of PLD. Thus one action site for the inhibitory effect of insulin on VLDL assembly could to be located at the second step that regulates the addition of the lipids into "pre VLDL" particles. This cascade explains why insulin in vivo acutely inhibits specifically the production rate of triglyceride-rich VLDL 1 particles and possibly explains why this action is impaired in Type 2 diabetes $[47,50,54,55]$.

An interesting turn on the potential sites of insulin in regulating VLDL metabolism in the liver arose form the observations that insulin regulates the expression of the sterol regulatory element-binding protein-1c (SREBP-1c) in the liver [56]. The novelty of this finding is that hyperinsulinaemia per se up-regulates the expression of SREBP-1c which is followed by the activation of enzymes for lipogenesis, including fatty acid synthase (FAS) and acetyl Co A carboxylase (ACC). These enzymes are the key factors stimulating de novo lipogenesis (DNL) in the liver. Importantly, the up-regulation of SREBP-1c mRNA is seen in the setting of down-regulation of IRS-2-mediated insulin signalling pathway in the insulin-resistant state. Decisive evidence exists for the insulin induced expression of SREBP-1c [57]. This action of insulin is explained by IRS-1-PI 3 kinase pathway [58]. Overall SREBP-1c seems to have a crucial role in the regulation of triglyceride accumulation in the liver [59]. High rates of DNL are invariably associated with a shift of cellular metabolism from lipid oxidation to lipid storage in the liver increasing the availability of triglycerides for VLDL assembly [53].

Another factor that contributes to the storage pool of triglycerides in hepatocytes is the flux of free fatty acids into the liver that is increased in the insulinresistant states [53]. Notably NEFA are esterified before lipid droplets are formed and used for the assembly of VLDL [51]. It is conceptualized that the triglyceride storage depot constitutes a temporary buffer that prevents the reflection of wide excursion of plasma NEFA directly into VLDL secretion. This concept is supported by the evidence from kinetic studies where acute fluctuations of plasma NEFA are not followed by concomitant changes in the production of total VLDL apo B. Table 1 shows total VLDL apo B production rate and plasma NEFA concentrations in
Table 1. Variation of plasma NEFA and VLDL apo B production rate

\begin{tabular}{llc}
\hline Study & $\begin{array}{l}\text { VLDL apoB } \\
\mathrm{mg} / \mathrm{dl}\end{array}$ & $\begin{array}{l}\text { NEFA } \\
\mu \mathrm{mol} / 1\end{array}$ \\
\hline Saline* & $930 \pm 73$ & $494 \pm 62$ \\
Insulin* $^{*}$ & $645 \pm 59^{\mathrm{a}}$ & $71 \pm 14^{\mathrm{b}}$ \\
Acipimox & $810 \pm 104$ & $75 \pm 20^{\mathrm{b}}$ \\
Heparin* & $824 \pm 45$ & $1073 \pm 81^{\mathrm{b}}$ \\
\hline
\end{tabular}

The data is based on studies in healthy men $(n=15$ for saline, $n=12$ for insulin, $n=8$ for acipimox and for heparin) [47, 60, 61]. Total VLDL production is a sum of VLDL 1 and direct VLDL 2 apo B production calculated from kinetic parameters at $4.5 \mathrm{~h}$ during the turnover study. The concentration of NEFA represents the mean value of measures between $2 \mathrm{~h}$ and $8 \mathrm{~h}$. The results are means \pm SE. ${ }^{a} p<0.01,{ }^{b} p<0.001$ compared with Saline studies

studies where either insulin infusion or acipimox, an anti-lipolytic agent were used to suppress plasma NEFA concentrations or heparin-induced lipolysis to increase plasma NEFA concentrations [47, 60, 61]. Firstly despite similar suppression of NEFA during insulin infusion and acipimox administration only insulin significantly suppressed total VLDL apo B production due to the inhibition of large VLDL 1 apo B production. Thus the acute inhibitory action of insulin on VLDL production cannot be explained only by the profound suppression of NEFA concentrations by hyperinsulinism but the data confirm a direct inhibitory action of insulin on VLDL 1 production. Of note, the lowering of NEFA by acipimox was associated with a shift towards smaller and denser VLDL 2 apoB production while the amount of total VLDL apo B remained constant [60]. When plasma NEFA concentration was increased twofold by using heparin infusion there was no change in the total VLDL apo B production [61]. Indirect evidence is provided by the data showing that in humans neither fasting plasma NEFA concentration nor the sensitivity of insulin-mediated suppression of plasma NEFA are determinants of fasting VLDL-Tg secretion rates [62]. In contrast, chronically increased flux of NEFA to the liver increases the cytosolic triglyceride storage pool and promotes VLDL overproduction, reducing post-translational degradation of apo B and overexpression of MTP, both associated with insulin resistance $[42,63]$. In this context solid data confirm the overproduction of VLDL triglycerides in Type 2 diabetes $[64,65]$ whereas the data on VLDL apo B production have been partly controversial $[65,66,67,68]$.

The dysregulation of fat metabolism in the liver could be a key factor leading to the increase of large VLDL 1 particles in insulin resistance. Taken together the machinery driving VLDL assembly in the liver includes (i) impaired insulin signalling via PI3 kinase pathway that enhances lipid accumulation to "nascent" VLDL particles, (ii) up-regulation of 
SREBP-1C that stimulates de novo lipogenesis, (iii) excess availability of "fat" in hepatocytes that stabilizes apo B 100. There has been accumulating evidence showing that hepatic steatosis is a feature of dyslipidaemia and insulin resistance [69, 70, 71]. Nonalcoholic fatty liver disease (NAFLD) is closely associated with hypertriglyceridaemia, low HDL cholesterol, hyperinsulinaemia and insulin resistance and glucose intolerance [71]. Notably there is a close positive correlation between fasting plasma triglycerides and liver fat quantitated by using proton spectroscopy in humans [72]. Thus the factors modulating the amount of fat in the liver have become a topic of urgent interest. Whether the amount of fat in the liver is the cause or the consequence of insulin resistance remains an issue to be resolved but obviously it is highly relevant to insulin resistance and dyslipidaemia as well as Type 2 diabetes [73].

\section{Is diabetic dyslipidaemia a postprandial phenomenon?}

Fat intolerance in Type 2 diabetes

Recently extensive attention has been focused on post-challenge glucose values as a risk factor of CVD in subjects with impaired glucose tolerance as well as in patients with Type 2 diabetes [74, 75]. Consequently the fluctuation of post-challenge glucose concentrations has become an important target of glucose control. The recognition that the postprandial state is a cluster of metabolic abnormalities could open new targets for therapies aiming to prevent cardiovascular complications [76]. Postprandial lipemia (fat intolerance) is a distinct component of diabetic dyslipidaemia $[7,8,77,78]$. Several studies have shown that the response of plasma triglycerides to a standard fat load is much greater in Type 2 diabetic subjects than in non-diabetic subjects matched for age, sex and BMI [7, 8, 77, 78, 79]. Importantly, the peak concentration of plasma triglycerides are achieved at 4 to $6 \mathrm{~h}$ after the fat load. Thus the time course of $\mathrm{Tg}$ response is markedly different from that observed after a glucose load where glucose concentrations are back at the baseline level at 3 to $4 \mathrm{~h}$. This difference in time course is critical when we consider the response of lipids to consecutive meals eaten during a day. Recently the diurnal profile of plasma triglycerides was followed using an ambulatory plasma triglyceride measurement device in Type 2 diabetic patients selected on the basis of normal fasting triglyceride concentration $(<2.2 \mathrm{mmol} / \mathrm{l})$ (Fig. 3) [80]. The triglyceride profile shows that after breakfast the triglyceride concentrations gradually increased after consecutive meals and the peak concentration was achieved between dinner and bedtime. In this context it is important that the fasting triglycerides represented the nadir

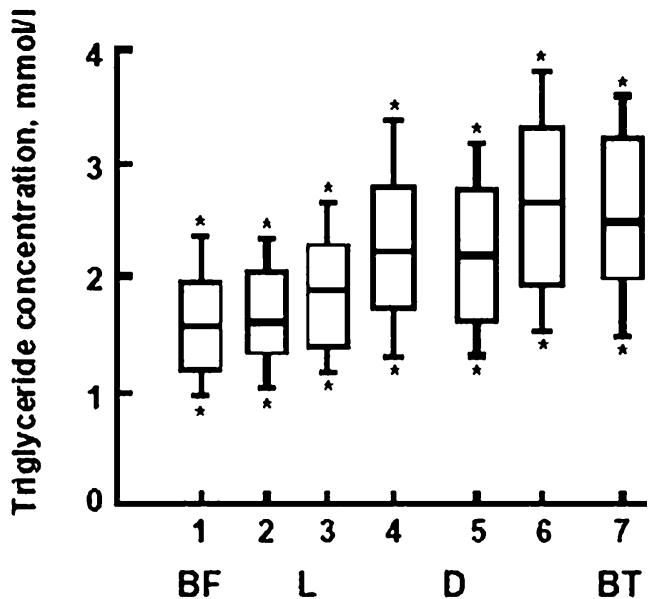

Fig. 3. The daytime triglyceride profile of Type 2 diabetic subjects $(n=81)$ with normal fasting triglyceride concentrations $(<2.2 \mathrm{mmol} / \mathrm{l})$ showing the medians and 25-75th centiles (box). The numbers 1-7 indicate the time points of measurements; fasting, post breakfast (B), before and after lunch (L), before and after dinner (D) and at bedtime (BD). Reproduced from reference [80] with permission of Diabetologia (Diabetologia 1997 ; 40:454-462)

of the 24-h triglyceride profile. A persuasive conclusion is that Type 2 diabetic patients are exposed to high triglyceride concentration throughout most of the $24 \mathrm{~h}$ a day.

In postprandial state TRLs represent a mixture of both apo B 48 and apo B100 containing lipoproteins. Indeed VLDL particles are the major component of TRLs after a fat load [81, 82]. These studies have shown that approximately $80 \%$ of the TRL increase in postprandial state is accounted for by the VLDL particles; the major component being the VLDL 1 species. This response is exaggerated in Type 2 diabetic patients. In fact the area under the curve (AUC) for VLDL 1 apo B 100 is approximately ten times higher than that for VLDL apo B 48 [83]. This difference in the pool sizes of apo B 48 and apo B 100 containing TRLs is considered to be mainly due to striking differences in the production rates of these particles [44]. The data on the catabolic rates of apo B100 and apo B48 have been inconsistent but most recent findings suggest that apo B100 can be removed faster than apo B48 [44]. In summary, TRLs contain much more hepatically than intestinally-derived particles within the density of chylomicrons and large VLDL particles. Ample evidence suggests that the increase of TRLs affects the metabolism of LDL and HDL subclasses. Although there is no change in LDL size after a single oral fat load we observed a highly significant negative correlation between the response of VLDL $1 \mathrm{Tg}$ and fasting LDL size as well as fasting HDL cholesterol (Fig. 4) [83]. These findings indicate that the continuous triglyceride exposure over the day is a key determinant of both LDL size and HDL cholesterol. 


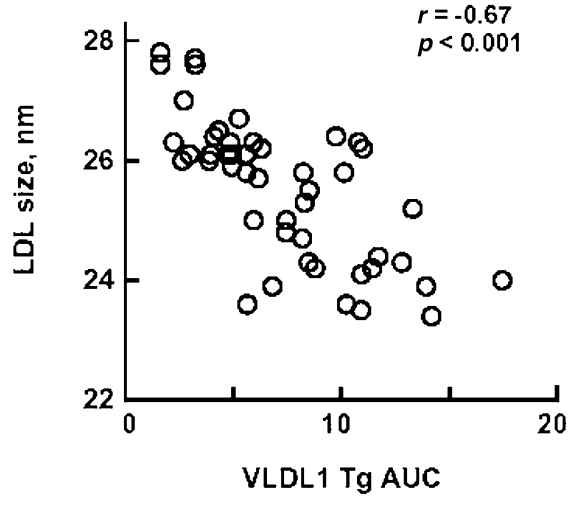

Fig. 4. Scattergrams showing the strong negative relationships in Type 2 diabetic subjects of LDL size (nm) (left panel) and HDL cholesterol (mmol/l) (right panel) and triglyceride response (AUC, area under the curve) in VLDL 1 fraction to a standardized oral fat load. Associations were analysed using Person's correlation analysis. Reproduced from reference [83] with permission of Diabetes Metabolism Research Review (Diabetes Metab Res Rev 2002; 18:484-490)

The mechanisms behind the excessive postprandial lipemia in Type 2 diabetes

The initial step in TRL metabolism is the hydrolysis of lipids by LPL bound to heparin sulfate proteoglycans (HSPG) at endothelial cells [78]. Triglycerides in large lipoproteins are hydrolyzed faster than in smaller particles. Thus, the flux of chylomicrons after a fatrich meal will impede the lipolysis of VLDL particles due to the competion for the contact with LPL $[8,78$, $84,85,86]$. Consequently the delipidation process of VLDL particles are slowed down and the residence time of these particles in circulation is prolonged. These processes are exaggerated in the situations where VLDL 1 production is excessive as exemplified by the failure of insulin to suppress VLDL 1 production in Type 2 diabetes $[8,50]$. A second factor impeding the lipolytic rate is the reduction of LPL activity commonly found in Type 2 diabetes [9, 11, 85, 87]. LPL activity is regulated by insulin and its actions are impaired in insulin resistance and Type 2 diabetes. Recent data confirmed that LPL activity in adipose tissue is indeed a determinant of postprandial triglyceride excursions in non-diabetic subjects [87]. In this study adipose tissue LPL activity also correlated negatively with the insulin resistance index. The carrier status of LPL gene mutations that are relatively common like N291S and D9 N, can aggravate the postprandial lipemia $[88,89]$. A third potential mechanism is the impaired clearance of remnant particles by liver receptors (LDL receptor and LRP) [85, 86]. Lipoprotein uptake is preceeded by trapping of remnants in the vicinity of receptors. HSPG, LPL, hepatic lipase as well as apo E can act as bridging proteins and thus modulate the removal of remnants. Recently reduced synthesis of HSPG core protein perlican was reported

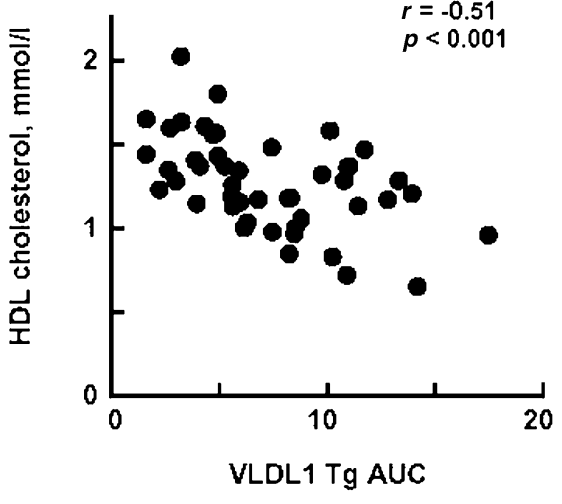

in streptosotozin diabetic mice together with concomitant delayed clearance of apo B 48 containing lipoproteins [90].

Whether there is also overproduction of apo B48 containing particles in the insulin resistant state and in Type 2 diabetes is a debated issue. The induction of the insulin resistant state in fructose-fed hamsters is associated with overproduction of apo B 48 containing particles [91]. There is also evidence that intestinal MTP is increased in diabetic animals and this could enhance the formation of apo B 48 containing particles $[86,91]$. Further studies are needed to delineate the exact contribution of intestinal overproduction of apo B 48 lipoproteins in diabetes to the postprandial lipemia in humans. Taken together the regulation of postprandial TRL metabolism is a complex process where several subsequent steps could be fundamentally altered in Type 2 diabetes.

\section{Is postprandial lipidemia a hazard?}

The important implication is that postprandial lipemia has severe adverse consequences at the level of the arterial wall. A number of studies have shown that postprandial lipemia is linked with the endothelial dysfunction and generation of oxidative stress in Type 2 diabetic patients [92, 93, 94, 95]. Remnant particles particularly cholesterol ester rich remnants are considered to be highly atherogenic $[8,9,78,85,86]$. Recent data suggest that apo B 48 and apo B 100 containing lipoproteins are probably equally atherogenic [96]. Both apoproteins can bind effectively to proteoglycans, the former via a newly identified binding segment of apo B 48 masked in apo B 100 [96] and the latter via a different domain [97]. In concert postmeal metabolic excursions comprise a cluster of potentially highly atherogenic perturbations that could be more important in terms of damaging the arterial wall than those due to hyperglycaemia [76]. In addition lipoproteins and remnants can also interact with coagulation factors [98, 99]. In this context a persuasive hypothesis is that a fatty meal is a trigger for acute coronary syndrome [99]. Therefore it is not suprising that the postprandial state is in the spotlight of current research. 


\section{Metabolic alterations of LDL subclasses in Type 2 diabetes}

\section{Distribution and properties of LDL species}

LDL comprises a heterogeneous spectrum of particles, which differ in size, density, chemical composition and atherogeneity. The most common way to separate LDL subclasses has been the use of gradient gel electrophoresis (GGE). Small dense LDL is defined as a particle with a mean diameter of the major LDL-peak less than $25.5 \mathrm{~nm}$ and it is the major component in pattern B, whereas pattern A consists of LDL particles with a greater diameter [100]. Small dense LDL differs from large LDL with respect to chemical composition and binding affinity to proteoglycans. Small dense LDL contains less polar lipids than large LDL particles (35.6 vs 63.3\%) [101]. The key variant is the cholesterol to triglyceride ratio of LDL particles that is decreased in small dense LDL particles [102]. The conformation of apo B 100 is distinct between the LDL subspecies and this is reflected in the different exposure of apo B 100 on the surface of LDL particles. The key difference is that specific segments which mediate the binding of apo B 100 to proteoglycans are exposed on the surface of small dense LDL particles [96, 97, 101, 103].

Several studies have shown that small dense LDL is an integral feature of diabetic dyslipidaemia even in normal or subnormal LDL cholesterol concentrations $[18,104,105,106,107,108]$. Recent data suggest that about 40 to $50 \%$ of Type 2 diabetic patients have a preponderance of small dense LDL particles [109, $110,111]$. There is a stepwise decrease of LDL size when subjects with normal glucose tolerance are compared to those with impaired glucose tolerance and clinical diabetes [108]. The decrease in LDL size seems to be greater in women than in men. Small dense LDL correlates with measures of insulin resistance but after controlling for triglycerides and HDL cholesterol, no association prevails between LDL size and insulin sensitivity [107, 112, 113, 114, 115]. In agreement several studies have confirmed that the concentration of plasma triglyceride is the single most important determinant of the variability of LDL size explaining nearly $50 \%$ of the variation in LDL size $[114,115]$. Our recent data suggest that VLDL 1 triglyceride is the major predictor of LDL size in Type 2 diabetic subjects $(r=-0.580 p<0.001, n=229)$ as well as in non-diabetic subjects $(r=-0.491, p<0.01, n=72)$ (Fig. 5). This observation is in agreement with the kinetic data showing that large VLDL 1 particles are the ancestors of small dense LDL species [45]. The prerequisites for the formation of small dense LDL include diminished lipolysis and long residence time of VLDL 1 particles in circulation. The long residence time favours the excess core lipid exchange of triglycerides and cholesterol esters between TRLs and

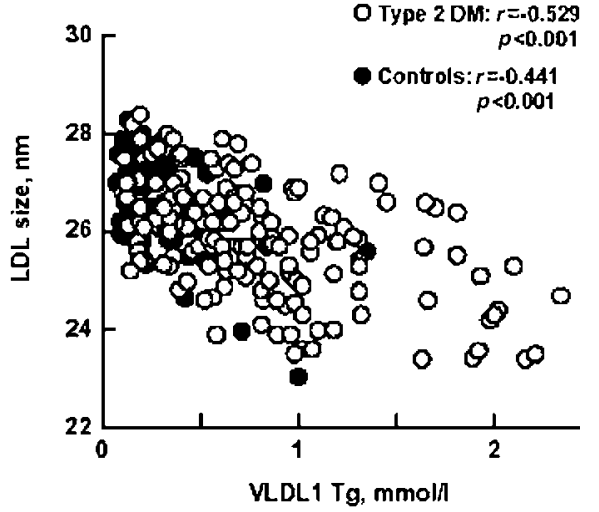

Fig. 5. The relationship between fasting concentrations of VLDL $1 \mathrm{Tg}$ and LDL size in Type 2 diabetic patients $(n=232)$ $(\bigcirc)$ recruited for FIELD study and in age and sex matched healthy control subjects $(n=72)(\bigcirc)$ (Hiukka A et al., unpublished)

LDL (Fig. 6). This exchange of lipids is mediated via the action of cholesterol ester transfer protein (CETP). In this process LDL becomes depleted in cholesterol esters but enriched in triglycerides that are a preferencial substrate for hepatic lipase action. Hepatic lipase is commonly increased in subjects with Type 2 diabetes and consequently the prevailing metabolic conditions favour the formation of small dense LDL particles $[12,13,14,46]$. Since each LDL particle contains one molecule of apo B 100, the number of LDL particles is increased if particles are small and dense. The apo B 100 concentration increases in direct relation to the number of LDL particles. Taken together the absolute concentration of LDL cholesterol can be misleading in the evaluation of CVD risk in subjects with small dense LDL [104].

Why is small dense LDL highly atherogenic?

A several set of observations witnesses that the reduced LDL size is linked to the increased risk of CHD $[116,117,118,119]$. Both LDL size and the number of particles seems to increase synergistically the risk of CHD [120, 121]. Recently convincing tenets seem to explain the atherogeneity of small dense LDL particles. Solid data shows that LDL size is a strong determinant of endothelial function in Type 2 diabetic subjects as well as in normal healthy men $[122,123,124$, 125]. In our study the subjects with small dense LDL, but comparable LDL cholesterol concentration, had impaired response to endothelium-dependent vasodilator acetylcholine $[124,125]$. Whether or not this association is causative is not clear but the data suggest that small dense LDL can at least partly explain the adverse effects on vascular function in Type 2 diabetes. It is generally considered that small particle size favours the penetration of LDL particles into the arterial intima [126]. In addition the prolonged residence 


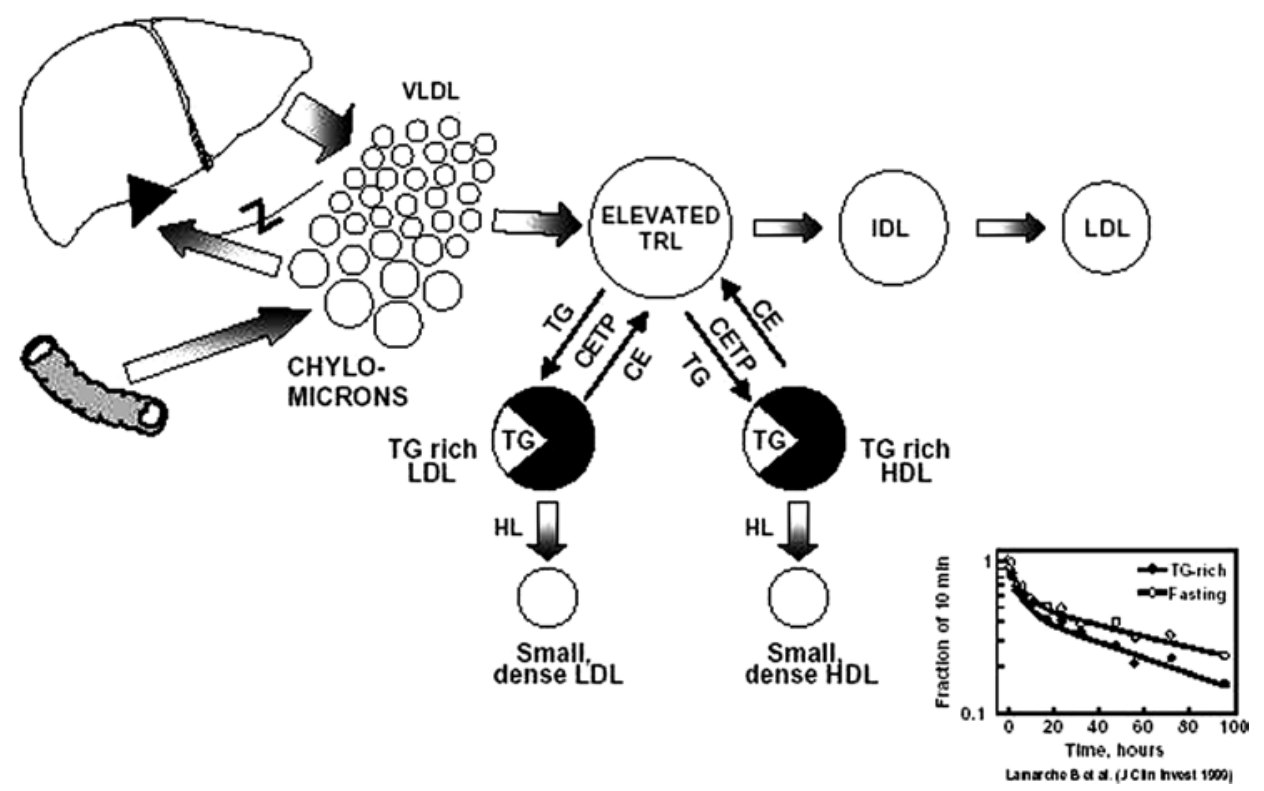

Fig. 6. Proposed mechanisms behind the generation of small dense LDL and small dense HDL in Type 2 diabetes. The increase of TRLs due to both exaggerated postprandial lipemia and VLDL 1 overproduction in the face of low LPL activity results in the long-residence time of TRL particles in circulation. These favour the exchange of core lipids, mediated by cholesterol ester transfer protein (CETP), between both LDL and TRLs and HDL and TRLs leading to triglyceride enrichment of both LDL and HDL particles. These particles are good substrate for hepatic lipase which is commonly increased in Type 2 diabetes [14]. The hydrolysis of HDL particles produces smaller particles that have enhanced catabolic rate as shown in the subscript panel. Taken together there is a symmetry of mechanisms leading to formation of small dense LDL and HDL. Reproduced from reference [7] with permission of Elsevier (The Lancet, 1997, 350, Suppl 1, 20-23)

time of small dense LDL due to its poor binding to LDL receptor gives more time for particles to infiltrate into the arterial intima. Recently it was reported that transvascular LDL transport rate is indeed increased in patients with Type 2 diabetes [127]. Surprisingly there was no correlation between LDL size and transvascular LDL transport. The authors suggest that the increased transvascular LDL transport reflects a general increase of transvascular permeability in diabetes. Irrespective of the mechanism, increased flux of lipoproteins results in subsequent deposition of LDL particles in the arterial wall. Small dense LDL particles have higher binding affinity to intimal proteoglycans than large LDL particles [128, 129, 130]. Additionally indirect binding via bridging molecules such as lipoprotein lipase and decorin further increase the retention of LDL in the arterial wall [131]. The retained LDL particles in the intima are exposed to modification under conditions of oxidative stress. Small dense LDL shows an increased susceptibility to oxidation and glycation of LDL further aggravating this susceptibility to oxidation $[132,133,134,135]$. A debated question is whether the size of LDL or its integral physical properties determine LDL oxidisability. Growing evidence suggest that free fatty compositions of LDL particles is the most important determinant of LDL oxidisability [136, 137]. Moreover the increased lability of cholesterol ester hydroperoxides in small dense LDL is a key feature of oxidative susceptibility [138]. Ultimately oxidized LDL in the inti$\mathrm{ma}$ is the trigger that initiates a cascade of processes leading to the formation of macrophage foam cells and the plaque formation.

\section{Metabolic alterations of HDL subclasses in Type 2 diabetes}

\section{Distribution and properties of HDL species}

A low concentration of HDL cholesterol is a dominant feature of diabetic dyslipidaemia. In most studies that have used precipitation methods the concentration of HDL 2 cholesterol is reduced more than that of HDL 3 [8]. However it should be recognized that HDL particles are the most malleable of lipoprotein species undergoing continuous remodeling in circulation via the actions of LPL, HL, CETP and phospholipid transfer protein (PLTP) [8, 139]. HDL particles can be separated by gradient gel electrophoresis (GGE) into five subpopulations that differ in size, composition and function. Fig. 7 illustrates profiles of HDL subclasses separated by GGE according to the size in a normal subject and in a patient with Type 2 diabetes. It is clear that the profiles are very different; the Type 2 diabetic patient lacks large HDL particles residing normally within the range of HDL 2 . There is a step-wise decrease of large buoyant HDL2b fraction over the tertiles of fasting triglycerides [140]. The mean HDL size defined by GGE has been reported to be reduced in the subjects with metabolic syndrome 


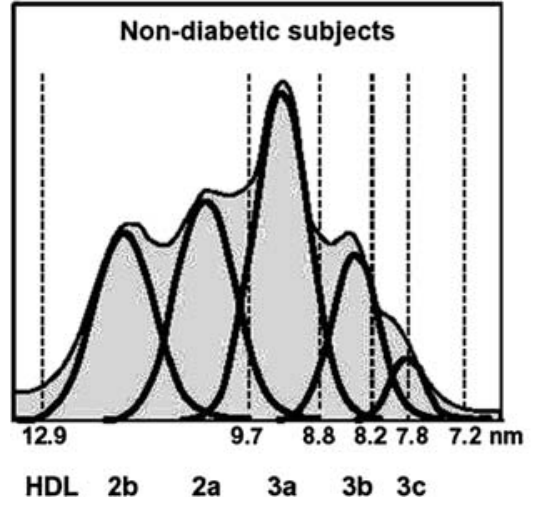

Fig. 7. Profiles of HDL subfractions in a non-diabetic subject and in a Type 2 diabetic patient separated by gradient gel electrophoresis. The thick bell-shaped lines represent Gaussian fitting of the scanline. The continuous line at the top of each panel is the original scanline. Vertical dotted lines are the fixed cut-points according to [178]. HDL subfractions are delineated from left to right according to the size (nm). In Type 2 diabetes there is a shift from large buoyant to small dense HDL particles. Reproduced from reference [140] with permission of Journal of Lipid Research (J Lipid Res 1995; 36:573-582)

[141]. Furthermore the particle size of HDL correlated with fasting plasma triglycerides as well as with LDL size. The authors proposed that small HDL is a new component of the metabolic syndrome.

HDL particles can also be separated according to their concentration of the two structural apoproteins A-I and A-II. Some HDL particles contain only apo A-I but not apo A-II (LpA-I), or other particles containing both apo A-I and A-II (LpA-I:A-II). We found in a cross sectional study that both apo A-I and A-II were reduced in patients with Type 2 diabetes [142]. As expected there was a consistent decrease in LpA-I:A-II particles in Type 2 diabetic patients. We also found that the ability of plasma from Type 2 diabetic subjects to promote cholesterol efflux in vitro from hepatoma cells was related to LpA-I:A-II concentrations rather than to LpA-I concentrations [143]. Thus Type 2 diabetic subjects showed a deficiency of Lp:A-I mediated reverse-cholesterol transport.

\section{Mechanisms behind lowering of HDL}

There are several cogent reasons for the lowering of HDL in diabetic dyslipidaemia. The increase of plasma triglycerides drives the exchange of core lipids between TRLs and HDL particles as between TRLs and LDL particles (Fig. 6) [8, 139, 144]. This process results in the triglyceride enrichment of HDL particles like LDL particles. Triglycerides in HDL, like in LDL, are a good substrate for hepatic lipase and the hydrolysis produces smaller particles and free apo A-I that is shed from the particle and cleared by the kidneys. Triglyceride enrichment of HDL has been ob-

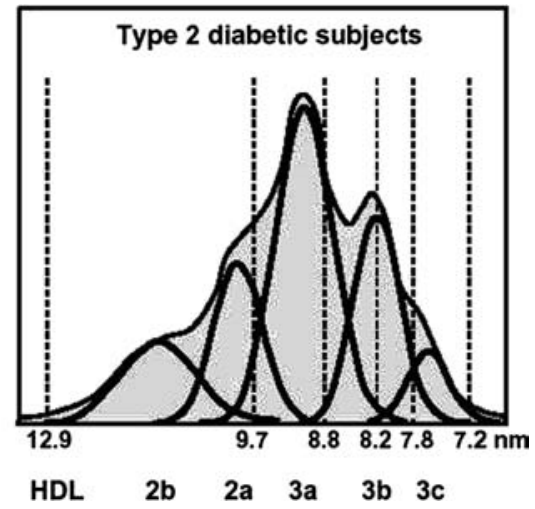

served to enhance in vivo clearance of HDL apo A-I in healthy men [145]. It has been shown that lipolysis of Tg enriched HDL particles by HL was required for the enhanced clearance rate of HDL [146]. These results highlight the concerted action of both HDL Tg enrichment and hepatic lipase action in the pathogenesis of HDL lowering. A number of studies have confirmed that the clearance rate of HDL is indeed enhanced in Type 2 diabetic patients [147, 148, 149]. In Type 2 diabetic subjects LPL activity was inversely related to HDL Tg concentrations and thus also contributed to the compositional changes of HDL and consequently the clearance rate of the particles [150]. Taken together there seems to be a symmetry of mechanism leading to the generation of small HDL and small LDL particles (Fig. 6).

Recent studies have shown new factors that are integral regulators of HDL metabolism and reverse cholesterol transport including the ATP cassette binding protein-1 (ABCA1) and the scavenger receptor BI (SR-BI) [151]. There is evidence that glucose regulates the expression of mRNA levels of ABCA-1, SR-BI and phospholipid transfer protein (PLTP) [152]. Additionally, PLTP an intravascular regulator of HDL metabolism is regulated by insulin or insulin resistance [153]. Whether insulin or insulin resistance also influences the expression of these gate-keeper proteins of cholesterol trafficking (ABCA-1, SR-BI) as well as the precise mechanism of action are the exciting targets of future research.

\section{Consequences of the increase of VLDL 1 particles}

Solid evidence suggests that the increase of TRLs, in particular, of large VLDL 1 particles in Type 2 diabetes is hazardous with respect to atherosclerosis. These metabolic consequences include (i) the increase of plasma triglycerides, (ii) accumulation of remnant particles in circulation, (iii) the generation of small dense LDL particles, and (iv) the lowering of HDL concentration as well as the reduction of HDL size. All these alterations comprise a cluster of highly atherogenic potential and thus the increase of VLDL 1 particles seems to be the major culprit in diabetic dyslipidaemia. 


\section{The principal objective of lipid management in Type 2 diabetes}

As described above diabetic dyslipidaemia is a cluster of lipid aberrations that are metabolically closely linked. A much debated question has been which individual lipoprotein aberration in diabetic dyslipidaemia is most atherogenic and should be the primary target of lipid management. This debate cannot be considered fully relevant but is at least partly sanctimonious and has given the excuse for therapeutic negligence. The most powerful atherogenic components are (i) small dense LDL, (ii) remnant particles, and (iii) the low concentration of HDL with its unfavorable compositional alterations. The coexistence of these three factors strongly aggravates the lipid accumulation in arterial wall and the formation of plaques [7, 9, 86, $126,139]$. Consequently all three factors should be the targets of therapy.

Recently Adult Treatment Panel III (ATP III) designated diabetes as a CHD equivalent [6]. The reason for this fundamental step was the undisputed evidence that Type 2 diabetic subjects without a prior history of myocardial infarction (MI) have as a high risk of CHD as non-diabetic patients who have had a previous MI $[4,5]$ as well as the extremely poor short-term prognosis of Type 2 diabetic subjects after their first MI $[154,155]$. ATP III and ADA guidelines identified LDL cholesterol as the first priority of lipid lowering and the optimal level was set $<2.6 \mathrm{mmol} / \mathrm{l}[6,156]$.

Landmark secondary prevention studies (4S, CARE, LIPID) have provided strong evidence of the clinical benefits of LDL-lowering in people with diabetes [157, 158, 159]. The Heart Protection study (HPS) included 5348 people with diabetes and 2279 with no previous CHD [160]. The HPS showed that simvastatin reduced vascular events by $24 \%$ in people with diabetes independently of the initial LDL cholesterol concentration. Notably at the entry to the study the mean concentration of LDL averaged $3.23 \mathrm{mmol} / \mathrm{l}$ and $40 \%$ of the subjects had LDL cholesterol $<3.0 \mathrm{mmol} / 1$ [161]. Thus the Type 2 diabetic subjects included in the HPS had a very similar lipid profile to those seen in the UKPDs study [162] and DAIS cohort [163].

Thus the benefits of statins therapy in people with Type 2 diabetes can no longer be questioned recognizing also the fact that statins have additional properties that can increase their effectiveness beyond the lipid lowering that is mainly related to lowering of LDL and decrease of LDL particle number [164, 165, 166]. The secondary goal of lipid lowering is to achieve the optimal concentrations of plasma triglycerides at less than $1.7 \mathrm{mmol} / \mathrm{l}$ and HDL cholesterol greater than $1.15 \mathrm{mmol} / \mathrm{l}[6,156]$. Recent data from two intervention trials, Veterans Affairs HDL Intervention Study (VA-HIT) and Diabetes Atherosclerosis Intervention Study (DAIS), using fibrate (VA-HIT, gemfi- brozil and DAIS; fenofibrate) compared with placebo have given encouraging results [163, 167]. In both trials the fibrate treatment raised HDL cholesterol and lowered plasma triglycerides. These changes were associated with statistically significant clinical benefits (VA-HIT) and beneficial changes in angiographic parameters of focal stenosis (DAIS). The question whether patients with LDL cholesterol lower than $3.4 \mathrm{mmol} / \mathrm{l}$ but with the atherogenic lipid triad will benefit more from correction of the lipid triad by fibrates than from lowering of LDL cholesterol by statins remains to be established in ongoing clinical trials (FIELD, Fenofibrate Intervention and Event Lowering in Diabetes and ACCORD, Action to control Cardiovascular Risk in Diabetes; http://www.accordtrial.org).

\section{New perspectives of lipid management in Type 2 diabetes}

The peroxisome proliferator-activator receptors (PPARs) play a central role in the regulation of lipid and lipoprotein metabolism. In the liver the target genes of PPAR- $\alpha$ action include several genes that regulate lipoprotein metabolism including the expression of apo A-I, A-II and apo C-III, LPL gene and genes of enzymes involved in beta-oxidation [168]. A substantial wealth of data showing that the well known lipid or lipoprotein effects of fibrates can be explained by the activation of PPAR- $\alpha$ resulting in either stimulation or suppressing of the target genes [168]. The discovery of PPAR- $\alpha$ as the target of fibrate action has opened a renaissance for fibrates to correct the key lipoprotein abnormalities of diabetic dyslipidaemia [169]. The activation of both PPARs $\alpha$ and $\gamma$ seems to promote the expression of $A B C A 1$ gene via LXR activation and consequently enhance the reverse cholesterol transport $[170,171]$. This action explains the consistent increase of HDL cholesterol induced by thiazolidinediones (TZDs) [172]. Why the responses of plasma triglycerides and LDL-cholesterol are variable between different TZDs is an open issue. Most recent evidence suggests that PPARs also modulate inflammation response and lipid homeostasis of macrophages in entholial cells [173]. Conceptually, the development of PPAR $\alpha / \gamma$ agonists represents a promising line to produce tailored compounds that can correct both pertubations of lipid metabolism and insulin resistance. Recently a dual PPAR $\alpha / \gamma$ agonist (LY 465608) has been reported to improve glycaemia as well as lipid parameters in the $d b / d b$ mouse [174].

The recognition that overproduction of large VLDL particles is the culprit of diabetic dyslipidaemia pinpoints the regulatory steps in VLDL assembly as the critical target of drug action. Interestingly in primary hepatocytes PPAR $\alpha$ agonist (WY 14643) decreased the synthesis and secretion of triglycerides in the face of increased synthesis of apo B 100 [175]. The end re- 
sult was the formation of more apo B 100 containing particles with fewer triglycerides, i.e. a shift from large VLDL to smaller VLDL particles. Another interesting observation is that in the fructose-fed hamster with insulin resistance and mild hypertriglyceridaemia rosiglitazone treatment improved hepatic insulin resistance that was followed with a reduction of MTP expression and VLDL assembly and secretion linked to reduced intracellular apo B stability [43]. Of interest, PPAR- $\alpha$ deficiency is associated with lipid accumulation in the liver [176]. The complement to these studies is the observation that PPAR- $\gamma$ agonist in humans reduced fat in the liver [177]. These observations indicate that the activation of PPAR $\alpha$ and PPAR- $\gamma$ can influence the VLDL assembly at several sites and provide an option to tailor more efficient drugs that target the initial sites behind diabetic dyslipidaemia in the liver.

\section{Concluding remarks}

The rapid increase of our understanding of the complex pathophysiology of diabetic dyslipidaemia will hopefully be translated to better a treatment of diabetic dyslipidaemia. Although the clinical benefits of statin therapy are clear, it is widely accepted that there is a need for therapy beyond statins based on the specific features of diabetic dyslipidaemia. It is quite clear that the focus will shift to the liver and the complex but exciting world of transcription factors including PPARs, SREBP-1C and LXRs. Future research will hopefully provide new more specific drugs for vascular protection to relieve the heavy burden of CHD in diabetes. If Claude Bernard would live today he would probably state "The liver is a factory that produces lipids and glucose in excess, both products being hallmarks in diabetes and hazards for vascular wall".

Sources. This 2002 Claude Bernard Lecture of European Association for the Study of Diabetes is based on the studies of lipids and lipoprotein pathophysiology and metabolism in people with Type 2 diabetes and the relationship to CHD by the author, her Finnish and international collaborators and colleagues over the last two decades. Additionally the review aims to cover the most important literature published in the field over the last 5 years and seminal prior contributions.

Acknowledgements. The authors's work cited in this review was supported by grants from the Sigrid Juselius Foundation, the Finnish Heart Foundation, Helsinki University Central Hospital Research Foundation, The Academy of Finland and the Finnish Diabetes Association, Helsinki, Finland. The author gratefully acknowledges the fundamental contributions of her collaborators and postdoctoral fellows to the work discussed in this review. The skillful assistance of the research nursing and laboratory staff of the Department of Medicine, Helsinki University Central Hospital, Helsinki, Finland is greatly appreciated. Ms. H. Laakkonen and A.-M. Syrjänen provided excellent secretarial assistance in the preparation of this manuscript. The artistic work by Ms. S. Aarnio for helping with the figures is also appreciated.

\section{References}

1. Turner R C, Millns H, Neil HAW et al. (1998) Risk factors for coronary artery disease in non-insulin dependent diabetes mellitus: United Kingdom prospective diabetes study (UKPDS:23). BMJ 316:823-828

2. Isomaa B, Lahti K, Almgren P et al. (2001) Cardiovascular morbidity and mortality associated with the metabolic syndrome. Diabetes Care 24:683-689

3. Zimmet P, Alberti KGMM, Shaw J (2001) Global and societal implications of the diabetes epidemic. Nature 414:782-787

4. Haffner S M, Lehto S, Rönnemaa T et al. (1998) Mortality from coronary heart diseases in subjects with type 2 diabetes and in nondiabetic subjects with and without prior myocardial infarction. N Engl J Med 339:229-234

5. Malmberg K, Yusuf S, Gerstein H C et al. (2000) Impact of diabetes on long-term prognosis in patients with unstable angina and non-Q-wawe myocardial infarction. Circulation 102:1014-1019

6. Executive summary of the third report of the National Cholesterol Education Program (NCEP) (2001) Expert panel on detection, evaluation, and treatment of high blood cholesterol in adults (Adult Treatment Panel III). JAMA 285:2486-2497

7. Syvänne M, Taskinen M-R (1997) Lipids and lipoproteins as coronary risk factors in non-insulin dependent diabetes mellitus. Lancet 350 [Suppl 1]:20-23

8. Taskinen M-R (2001) Pathogenesis of dyslipidemia in type 2 diabetes. Exp Clin Endocrinol Diabetes 109:173-181

9. Ginsberg HN (2002) New perspectives in atherogenesis: role of abnormal triglyceride-rich lipoprotein metabolism. Circulation 106:2137-2142

10. Packard CJ, Shepherd J (1997) Lipoprotein heterogeneity and apolipoprotein B metabolism. Aterioscler Thromb Vasc Biol 17:3542-3556

11. Taskinen M-R (1987) Lipoprotein lipase in diabetes. Diabet/Metab Rev 3:551-570

12. Kasim SE, Tseng K, Jen K-LC et al. (1987) Significance of hepatic triglyceride lipase activity in the regulation of serum high density lipoproteins in type II diabetes mellitus. J Clin Endocrinol Metab 65:183-187

13. Baynes C, Henderson A D, Anyaoku V et al. (1991) The role of insulin insensitivity and hepatic lipase in the dyslipidaemia of type 2 diabetes. Diabet Med 8:560-566

14. Tan KCB, Shiu SWM, Chu BYM (1999) Roles of hepatic lipase and cholesteryl ester transfer protein determining low density lipoprotein subfraction distribution in Chinese patients with non-insulin-dependent diabetes mellitus. Atherosclerosis 145:273-278

15. Tan CE, Forster L, Caslake MJ et al. (1995) Relations between plasma lipids and postheparin plasma lipases and VLDL and LDL subfraction patterns in normolipemic men and women. Arterioscler Thromb Vasc Biol 15:1839-1848

16. McEneny J, O'Kane MJ, Moles KW et al. (2000) Very low density lipoprotein subfractions in type 2 diabetes mellitus: alterations in composition and susceptibility to oxidation. Diabetologia 43:485-493

17. Taskinen M-R, Packard CJ, Shepherd J (1990) Effect of insulin therapy on metabolic fate of apolipoprotein B-containing lipoproteins in NIDDM. Diabetes 39:1017-1027 
18. Guérin M, Le Goff W, Lassel TS et al. (2001) Proatherogenic role of elevated CE transfer from HDL to VLDL 1 and dense LDL in type 2 diabetes. Arterioscler Thromb Vasc Biol 21:282-288

19. Leinonen ES, Leinonen PJ, Salonen JT et al. (2002) Reduced IGFBP-1 is associated with thickening of the carotid wall in type 2 diabetes. Diabetes Care 25:1807-1812

20. Shachter NS (2001) Apolipoproteins C-I and C-III as important modulators of lipoprotein metabolism. Curr Opin Lipidol 12:297-304

21. Wang CS, McConathy WJ, Kloer HU et al. (1985) Modulation of lipoprotein lipase activity by apolipoproteins. Effect of apolipoprotein C-III. J Clin Invest 75:384-390

22. Ebra T, Ramakrishnan R, Steiner G et al. (1997) Chylomicronemia due to apolipoprotein CIII overexpression in apolipoprotein E-null mice. Apolipoprotein CIII-induced hypertriglyceridemia is not mediated by effects on apolipoprotein. Eur J Clin Invest 99:2672-2681

23. Sehayek E, Eisenberg S (1991) Mechanisms of inhibition by apolipoprotein $\mathrm{C}$ of apolipoprotein E-dependent cellular metabolism of human triglyceride-rich lipoproteins through the low density lipoprotein receptor pathway. J Biol Chem 266:18259-18267

24. Briones ER, Mao SJ, Palumbo PJ et al. (1984) Analysis of plasma lipids and apolipoproteins in insulin-dependent and non-insulin-dependent diabetics. Metabolism 33:42-49

25. Campos H, Perlov D, Khoo C et al. (2001) Distinct patterns of lipoproteins with apo B defined by presence of apo $\mathrm{E}$ or apoC-III in hypercholesterolemia and hypertriglyceridemia. J Lipid Res 42:1239-1249

26. Tomiyasu K, Walsh BW, Ikewaki K et al. (2001) Differential metabolism of human VLDL according to content of ApoE and ApoC-III. Arterioscler Thromb Vasc Biol 21:1494-1500

27. Sacks FM, Alaupovic P, Moye LA et al. (2000) VLDL, apolipoproteins B, CIII, and E, and risk of recurrent coronary events in the cholesterol and recurrent events (CARE) trial. Circulation 102:1886-1892

28. Luc G, Fievet C, Arveiler D et al. (1997) Apolipoproteins $\mathrm{C}$-III and $\mathrm{E}$ in apoB- and non-apoB-containing lipoproteins in two populations at contrasting risk for myocardial infarction: the ECTIM study. Etude Cas Temoins sur Infarctus du Myocarde. J Lipid Res 37:508-517

29. Gervaise N, Garrigue M A, Lasfargues G et al. (2000) Triglycerides, apo C3 and Lp B:C3 and cardiovascular risk in type 2 diabetes. Diabetologia 43:703-708

30. Gabor J, Spain M, Kalant N (1980) Composition of serum very-low-density and high-density lipoproteins in diabetes. Clin Chem 26:1261-1265

31. Stalenhoef AFH, Demacker PNM, Lutterman JA et al. (1982) Apolipoprotein C in type 2 (non-insulin-dependent) diabetic patients with hypertriglyceridaemia. Diabetologia 22:489-491

32. Ishibashi S, Yamada N, Shimano H et al. (1989) Composition of very-low-density lipoproteins in non-insulin-dependent diabetes mellitus. Clin Chem 35:808-812

33. Mahley RW, Ji S-Z (1999) Remnant lipoprotein metabolism: key pathways involving cell-surface heparan sulfate proteoglycans and apolipoprotein. Eur J Lipid Res 40:1-16

34. Syvänne M, Rosseneu M, Labeur C et al. (1994) Enrichment with apolipoprotein $\mathrm{E}$ characterizes postprandial TG-rich lipoproteins in patients with non-insulin-dependent diabetes mellitus and coronary artery disease: preliminary report. Atherosclerosis 105:25-34

35. Tannock LR, Olin KL, Barret HR et al. (2002) Triglyceride-rich lipoproteins from subjects with type 2 diabetes do not demonstrate increased binding to biglycan, a vascular proteoglycan. J Clin Endocrinol Metab 87:35-40
36. Sparks JD, Sparks CE (1994) Insulin regulation of triglycerol-rich lipoprotein synthesis and secretion. Biochim Biophys Acta 1215:9-32

37. Zammit V A (1996) Role of insulin in hepatic fatty acid partitioning: emerging concepts. Biochem J 314:1-14

38. Chirieac D V, Chirieac L R, Corsetti J P et al. (2000) Glucose-stimulated insulin secretion suppresses hepatic triglyceride-rich lipoprotein and apoB production. Am J Endocrinol Metab 279: E1003-E1011

39. Lin MCM, Gordon D, Wetterau JR (1995) Microsomal triglyceride transfer protein (MTP) regulation in HEPG2 cells: insulin negatively regulates MTP gene expression. J Lipid Res 36:1073-1081

40. Kuriyama H, Yamashita S, Shimomura I et al. (1998) Enhanced expression of hepatic acyl-coenzyme A synthetase and microsomal triglyceride transfer protein messenger RNAs in the obese and hypertriglyceridemic rat with visceral fat accumulation. Hepatology 27:557-562

41. Bartels ED, Lauritsen M, Nielsen LB (2002) Hepatic expression of microsomal triglyceride transfer protein and in vivo secretion of triglyceride-rich lipoproteins are increased in obese diabetic mice. Diabetes 51:1233-1239

42. Taghibiglou C, Carpentier A, Van Iderstine SC et al. (2000) Mechanism of hepatic very low density lipoprotein overproduction in insulin resistance. J Biol Chem 275:8416-8425

43. Carpentier A, Taghibiglou C, Leung N et al. (2002) Ameliorated hepatic insulin resistance is associated with normalization of microsomal triglyceride transfer protein expression and reduction in very low density lipoprotein assembly and secretion in the fructose-fed hamster. J Biol Chem 277:28795-28802

44. Marsh JB, Welty FK, Lichtenstein AH et al. (2002) Apolipoprotein B metabolism in humans: studies with stable isotopelabeled amino acid precursors. Atherosclerosis 162:227-244

45. Packard CJ, Demant T, Stewart JP et al. (2000) Apolipoprotein $\mathrm{B}$ metabolism and the distribution of VLDL and LDL subfractions. J Lipid Res 41:305-317

46. Tan CE, Forster L, Caslake MJ et al. (1995) Relations between plasma lipids and postheparin plasma lipases and VLDL and LDL subfraction patterns in normolipemic men and women. Arterioscler Thromb Vasc Biol 15:1839-1848

47. Malmström R, Packard CJ, Watson TDG et al. (1997) Metabolic basis of hypotriglyceridemic effects of insulin in normal men. Arterioscler Thromb Vasc Biol 17:1454-1464

48. Lewis GF, Uffelman KD, Szeto LW et al. (1993) Effects of acute hyperinsulinemia on VLDL triglyceride and VLDL ApoB production in normal weight and obese individuals. Diabetes 42:833-842

49. Bioletto S, Golay A, Munger R et al. (2000) Acute hyperinsulinemia and very-low-density lipoprotein subfractions in obese subjects. Am J Clin Nutr 71:443-449

50. Malmström R, Packard CJ, Caslake M et al. (1997) Defective regulation of triglyceride metabolism by insulin in the liver in NIDDM. Diabetologia 40:454-462

51. Gibbons GF, Islam K, Pease RJ (2000) Mobilisation of triglycerol stores. Biochim Biophys Acta 1483:37-57

52. Olofsson S-O, Stillemark-Bilton P, Asp L (2000) Intracellular assembly of VLDL: two major steps in separate cell compartments. Trends Cardiovasc Med 10:338-345

53. Lewis GF, Carpentier A, Adeli K et al. (2002) Disordered fat storage and mobolization in the pathogenesis of insulin resistance ond type 2 diabetes. Endocr Rev 23:201-229

54. Phung TL, Roncone A, De Mesy Jensen KL et al. (1997) Phosphoinositide 3-kinase activity is necessary for insulindependent inhibition of apolipoprotein $B$ secretion by rat hepatocytes and localizes to the endoplasmic reticulum. Journal of Biological Chemistry 272:30693-30702 
55. Brown AM, Gibbons GF (2001) Insulin inhibits the maturation phase of VLDL assembly via a phosphoinositide 3-kinase-mediated event. Arterioscler Thromb Vasc Biol 21:1656-1661

56. Shimomura I, Matsuda M, Hammer RE et al. (2000) Decreased IRS-2 and increased SREBP-1 lead to mixed insulin resistance and sensitivity in livers of lipodystrophic and ob/ob mice. Mol Cell 6:77-86

57. Foufelle F, Ferré $P$ (2002) New perspectives in the regulation of hepatic glycolytic and lipogenic genes by insulin and glucose: a role for the transcription factor sterol ragulatory element binding protein-1c. Biochem J 366:377-391

58. Matsumoto M, Ogawa W, Teshigawara K et al. (2002) Role of the insulin receptor substrate 1 and phosphatidylinositol 3-kinase signaling pathway in insulin-induced expression of sterol regulatory element binding protein 1c and glucokinase genes in rat hepatocytes. Diabetes 51:1672-1680

59. Yahagi N, Shimano H, Hasty AH et al. (2002) Absence of sterol regulatory element-binding Protein-1 (SREBP-1) ameliorates fatty livers but not obesity or insulin resistance in Lepob/Lepob mice. J Biol Chem 277:19353-19357

60. Malmström R, Packard CJ, Caslake M et al. (1998) Effects of insulin and acipimox on VLDL 1 and VLDL 2 apolipoprotein B production in normal subjects. Diabetes 47:779787

61. Malmström R, Packard CJ, Caslake M et al. (1999) Effect of heparin-stimulated plasma lipolytic activity on VLDL apo B subclass metabolism in normal subjects. Atherosclerosis 146:381-390

62. Carpentier A, Patterson BW, Leung N et al. (2002) Sensitivity to acute insulin-mediated suppression of plasma free fatty acids is not a determinant of fasting VLDL triglyceride secretion in healthy humans. Diabetes 51:18671875

63. Ginsberg HN (2000) Insulin resistance and cardiovascular disease. J Clin Invest 106:453-458

64. Kissebah AH, Alfarasi S, Evans DJ et al. (1982) Integrated regulation of very low density lipoprotein triglyceride and apolipoprotein-B kinetics in non-insulin-dependent diabetes mellitus. Diabetes 31:217-225

65. Taskinen MR, Beltz WF, Harper I et al. (1986) Effects of NIDDM on very-low-density lipoprotein triglyceride and apolipoprotein B metabolism. Study before and after sulfonylurea therapy. Diabetes 113:522-526

66. Cummings MH, Watts GF, Umpleby AM et al. (1995) Increased hepatic secretion of very-low-density lipoprotein apolipoprotein B-100 in NIDDM. Diabetologia 38:959967

67. Howard BV, Abbot WGH, Egusa G, Taskinen MR (1987) Coordination of very-low-density lipoprotein triglyceride and apolipoprotein B metabolism in humans: effect of obesity and non-insulin-dependent diabetes mellitus. Am Heart J 113:522-556

68. Duvillard L, Pont F, Florentin E et al. (2000) Metabolic abnormalities of apolipoprotein B-containing lipoproteins in non-insulin-dependent diabetes: a stable isotope kinetic study. Eur J Clin Invest 30:685-694

69. Ryysy L, Häkkinen A-M, Goto T et al. (2000) Hepatic fat content and insulin action on free fatty acids and glucose metabolism rather than insulin absorption are associated with insulin requirements during insulin therapy in type 2 diabetic patients. Diabetes 49:749-758

70. Marchesini G, Brizi M, Bianchi G et al. (2001) Nonalcoholic fatty liver disease: a feature of the metabolic syndrome. Diabetes 50:1844-1850

71. Clark JM, Diehl AM (2002) Hepatic steatosis and type 2 mellitus. Current diabetes reports 2:210-215
72. Seppälä-Lindroos A, Vehkavaara S, Häkkinen A-M et al. (2002) Fat accumulation in the liver is associated with defects in insulin suppression of glucose production and serum free fatty acids independent of obesity in normal men. J Clin Endocrinol Metab 87:3023-3028

73. Yki-Järvinen H (2002) Ectopic fat accumulation: an important cause of insulin resistance in humans. J R Soc Med 95 [Suppl 42]: 39-45

74. De Vegt F, Dekker JM, Ruhé HG et al. (1999) Hyperglycaemia is associated with all-cause and cardiovascular mortality in the Hoorn population: the Hoorn study. Diabetologia 42:926-931

75. The Decode Study Group (2001) Glucose tolerance and cardiovascular mortality. Arch Intern Med 161:397-404

76. Heine RJ, Balkau B, Ceriello A et al. (2003) What does post-prandial hyperglycaemia mean? Diabet Med (in press)

77. De Man FHAF, Castro Cabezas N, van Barlingen HJJ et al. (1996) Triglyceride-rich lipoproteins in non-insulin-dependent diabetes mellitus: post-prandial metabolism and relation to premature atherosclerosis. Eur J Clin Invest 26:89108

78. Ginsberg HN, Illingworth R (2001) Postprandial dyslipidemia: an atherogenic disorder common in patients with diabetes mellitus. Am J Cardiol 88 [Suppl]:H9-H15

79. Syvänne M, Hilden H, Taskinen M-R (1994) Abnormal metabolism of postprandial lipoproteins in patients with non-insulin-dependent diabetes mellitus is not related to coronary artery disease. J Lipid Res 35:15-26

80. Heine RJ, Dekker J M (2002) Beyond postprandial hyperglycaemia: metabolic factors associated with cardiovascular disease. Diabetologia 45:461-475

81. Schneeman BO, Kotite L, Todd KM et al. (1993) Relationship between the responses of triglyceride-rich lipoproteins in blood plasma containing apolipoproteins B-48 and B100 to fat containing meal in normolipidemic humans. Proc Natl Acad Sci USA 90:2069-2073

82. Karpe F, Bell M, Björkegren J et al. (1995) Quantification of postprandial triglyceride-rich lipoproteins in healthy men by Retinyl Ester labeling and simultaneous measurement of apolipoproteins B-48 and B-100. Arterioscler Thromb Vasc Biol. 15:199-207

83. Vakkilainen J, Mero N, Schweizer A et al. (2002) Effects of nateglinide and glibenclamide on postprandial lipid and glucose metabolism in type 2 diabetes. Diabetes Metab Res Rev 18:484-490

84. Karpe F, Olivercrone T, Hamsten A et al. (1997) Chylomicron/chylomicron remnant turnover in humans: evidence for margination of chylomicrons and poor conversion of larger to smaller chylomicron remnants. J. Lipid Res 38:949-961

85. Goldberg IJ, Kako Y, Lutz EP (2000) Responses to eating: lipoproteins, lipolytic products and atherosclerosis. Curr Opin Lipidol 11:235-241

86. Tomkin GH, Owens D (2001) Abnormalities in apo B-containing lipoproteins in diabetes and atherosclerosis. Diabetes Metab Res Rev 17:27-43

87. Panarotto D, Rémillard P, Bouffard L et al. (2002) Insulin resistance affects the regulation of lipoprotein lipase in the postprandial period and in an adipose tissue-specific manner. Eur J Clin Invest 32(2):84-92

88. Mero N, Suurinkeroinen L, Syvänne M et al. (1999) Delayed clearance of postprandial large TG-rich particles in normolipidemic carriers of LPL Asn291Ser gene variant; relationship to insulin sensitivity. J Lipid Res 40:1663-1670

89. Talmud PJ (2001) Genetic determinants of plasma triglycerides: impact of rare and common mutations. Curr Atheroscler Rep 3:191-199 
90. Ebra T, Conde K, Kako Y et al. (2000) Delayed catabolism of apo B48 lipoproteins due to decreased heparin sulphate proteoglycan production in diabetic mice. J Clin Invest 105:1807-1818

91. Haidari M, Leung N, Mahbub F et al. (2002) Fasting and postprandial overproduction of intestinally derived lipoproteins in an animal model of insulin resistance. J Biol Chem 277:31646-31655

92. Fard A, Tuck CH, Donis JA et al. (2000) Acute elevations of plasma asymmetric dimethylarginine and impaired endothelial function in response to a high-fat meal in patients with type 2 diabetes. Arterioscler Thromb Vasc Biol 20:2039-2044

93. Evans M, Anderson RA, Graham J et al. (2000) Ciprofibrate therapy improves endothelial function and reduces postprandial lipemia and oxidative stress in type 2 diabetes mellitus. Circulation 101:1773-1779

94. Rongen GA, Tack CJ (2001) Triglycerides and endothelial function in type 2 diabetes. Eur J Clin Invest 31:560-562

95. Ceriello A, Taboga C, Tonutti L et al. (2002) Evidence for an independent and cumulative effect of postprandial hypertriglyceridemia and hyperglycemia on endothelial dysfunction and oxidative stress generation. Circulation 106:1211-1218

96. Flood C, Gustafsson M, Richardson PE et al. (2002) Identification of the proteoglycan binding site in apolipoprotein B48. J Biol Chem 277(35): 32228-32233

97. Skålen K, Gustafsson M, Rydberg EK et al. (2002) Subendothelial retention of atherogenic lipoproteins in early atherosclerosis. Nature 417:750-754

98. Doi H, Kugiyama K, Oka H et al. (2000) Remnant lipoproteins induce proatherothrombogenic molecules in endothelial cells through a redox-sensitive mechanism. Circulation 102:670-676

99. Anderson RA, Jones CJH, Goodfellow J (2001) Hypothesis: is the fatty meal a trigger for acute coronary syndromes. Atherosclerosis 159:9-15

100. Austin MA, Breslow JL, Hennekens CH et al. (1988) Low-density lipoprotein subclass patterns and risk of myocardial infraction. JAMA 260:1917-1921

101. Hurt-Camejo E, Camejo G, Sartipy P (2000) Phospholipase A2 and small, dense low-density lipoprotein. Curr Opin Lipidol 11:465-471

102. Otvos JD, Jayarajah EJ, Cromwell WC (2002) Measurements issues related to lipoprotein heterogeneity. Am J Cardiol 90 [Suppl]:I22-I29

103. Boren J, Lee I, Zhu W et al. (1998) Identification of the low density lipoprotein receptor-binding site in apolipoprotein B100 and the modulation of its binding activity by the carboxyl terminus in familial defective Apo-B100. J Clin Invest 101:1084-1093

104. Sniderman AD, Scantlebury T, Cianflone K (2001) Hypertriglyceridemic HyperapoB: the unappreciated atherogenic dyslipoproteinemia in type 2 diabetes mellitus. Ann Intern Med 135:447-459

105. Tilly-Kiesi M, Syvänne M, Kuusi T et al. (1992) Abnormalities of low density lipoproteins in normolipidemic type 2 diabetic and nondiabetic patients with coronary artery disease. J Lipid Res 33:333-342

106. Stewart MW, Laker MF, Dyer RG et al. (1993) Lipoprotein compositional abnormalities and insulin resistance in type 2 diabetic patients with mild hyperlipidemia. Arterioscl Thromb Vasc Biol 13:1046-1052

107. Lahdenperä S, Syvänne M, Kahri J et al. (1996) Regulation of low-density lipoprotein particle size distribution in NIDDM and coronary disease: importance of serum triglycerides. Diabetologia 39:453-461
108. Gray RS, Robbins DC, Wang Wenyu et al. (1997) Relation of LDL size to the insulin resistance syndrome and coronary heart disease in american indians. Arterioscler Thromb Vasc Biol 17:2713-2720

109. Feingold KR, Grunfield C, Pang M et al. (1992) LDL subclass phenotypes and triglyceride metabolism in noninsulin-dependent diabetes. Arterioscler Thromb 12:14961502

110. Caixàs A, Ordóñez-Llanos J, Leiva A de et al. (1997) Optimization of glycemic control by insulin therapy decreases the proportion of small dense LDL particles in diabetic patients. Diabetes 46:1207-1213

111. Koba S, Hirano T, Yoshino G et al. (2002) Remarkably high prevalence of small dense low-density lipoprotein in Japanese men with coronary artery disease, irrespective of the presence of diabetes. Atherosclerosis 160:249-256

112. Lahdenperä S, Sane T, Vuorinen-Markkola H et al. (1994) LDL particle size in mildy hypertriglyceridemic subjects: no relation to insulin resistance or diabetes. Atherosclerosis 113:227-236

113. Tchernof A, Moorjani S, Lamarche B et al. (1996) The dense LDL phenotype: association with plasma lipoprotein levels, visceral obesity, and hyperinsulinemia in men. Diabetes Care 19:629-637

114. Ambrosch A, Dierkes J, Mühlen I et al. (1998) LDL size distribution in relation to insulin sensitivity and lipoprotein pattern in young and healthy subjects. Diabetes Care 21:2077-2084

115. Rainwater DL (2000) Lipoprotein correlates of LDL particle size. Atherosclerosis 148:151-158

116. Austin MA, Breslow JL, Hennekens CH et al. (1988) Low density lipoprotein subclass patterns and risk of myocardial infarction. JAMA 260:1917-1921

117. Coresh J, Kwiterovich PO, Smith HH et al. (1993) Association of plasma triglyceride concentration and LDL particle diameter, density and chemical composition with premature coronary artery disease in men and women. J Lipid Res 34:1687-1697

118. Lamarche B, Tchernof A, Dagenals GR et al. (1997) Small, dense LDL particles and the risk of ischemic heart disease. Prospective results from the Québec Cardiovascular Study. Circulation 95:69-75

119. Gardner CD, Fortmann SP, Krauss RM (1996) Association of small low-density lipoprotein particles with the incidence of coronary artery disease in men and women. JAMA 276:875-881

120. St-Pierre AC, Ruel IL, Cantin B et al. (2001) Comparison of various electrophoretic characteristics of LDL particles and their relationship to the risk of ischemic heart disease. Circulation 104:2295-2299

121. Vakkilainen J, Steiner G, Ansquer J-C et al. (2003) Relationships between LDL particle size, plasma lipoproteins and progression of coronary artery disease. The diabetes atherosclerosis intervention study (DAIS). Circulation 107:1733-1737

122. Hogikyan RV, Galecki AT, Pitt B et al. (1998) Specific impairment of endothelium-dependent vasodilation in subjects with type 2 diabetes. J Clin Endocr Metab 83:1946-1952

123. Tan KC, Ai VH, Chow S et al. (1999) Influence of low density lipoprotein (LDL) subfraction profile and LDL oxidation on endothelium-dependent and independent $\mathrm{v}$ asodilation in patients with type 2 diabetes. J Clin Endocrinol Metab 84:3212-3216

124. Vakkilainen J, Mäkimattila S, Seppälä-Lindroos A et al. (2000) Endothelial dysfunction in men with small LDL particles. Circulation 102:716-721 
125. Mäkimattila S, Mäntysaari M, Liu M-L et al. (1999) Impaired endothelium-dependent vasodilation in type 2 diabetes. Diabetes Care 22:973-981

126. Chapman MJ, Guérin M, Bruckert E (1998) Atherogenic, dense low-density lipoproteins: Pathophysiology and new therapeutic approaches. Eur Heart J 19 [Suppl A]:A24A30

127. Kornerup K, Nordestgaard BG, Feldt-Rasmussen B et al. (2002) Transvascular low-density lipoprotein transport in patients with diabetes mellitus (type 2): a noninvasive in vivo isotope technique. Arterioscler Thromb Vasc Biol 22:1168-1174

128. Galeano NF, Milne R, Marcel YL et al. (1994) Apoprotein $\mathrm{B}$ structure and receptor recognition of triglyceride-rich low density lipoprotein (LDL) is modified in small LDL but not in triglyceride-rich LDL of normal size. J Biol Chem 269:511-519

129. Anber V, Griffin BA, Mc Connell M et al. (1996) Influence of plasma lipid and LDL-subfraction profile on the interaction between low density lipoprotein with human arterial wall proteoglycans. Atherosclerosis 124:261-271

130. Galeano NF, Al-Haideri M, Keyserman F et al. (1998) Small dense low density lipoprotein has increased affinity for LDL receptor-independent cell surface binding sites: a potential mechanism for increased atherogenity. J Lipid Res 39:1263-1273

131. Chait A, Wight TN (2000) Interaction of native and modified low-density lipoproteins with extracellular matrix. Curr Opin Lipidol 11:451-456

132. Tribble DL, Holl LG, Wood PD et al. (1992) Variations in oxidative susceptibility among six low density lipoprotein subfractions of differing density and particle size. Atherosclerosis 93:189-199

133. De Graaf J, Lemmers HLM, Hectors MPC et al. (1991) Enhanced susceptibility to in vitro oxidation of the dense low density lipoprotein subfraction in healthy subjects. Arterioscler Thromb 11:198-306

134. Lyons TJ, Jenkins AJ (1997) Lipoprotein glycation and its metabolic consequences. Current Opin Lipidol 8:174180

135. Onorato JM, Jenkins AJ, Thorpe SR et al. (2000) Pyridoamine, an inhibitor of advanced glycation reactions, also inhibits advanced lipoxidation reactions. Mechanism of action of pyridocamine. J Biol Chem 275:21177-21184

136. Dimitriadis E, Griffin M, Owens D et al. (1996) Lipoprotein composition in NIDDM. The effect of dietary oleic acid on composition and oxidisability and function of low and high density lipoproteins. Diabetologia 39:667-676

137. Scheffer PG, Bakker SJL, Popp-Snijders C et al. (2001) Composition of LDL determinant on its susceptibility to in vitro oxidation in patients with well-controlled type 2 diabetes. Diabetes Metab Res Rev 17:459-466

138. Chancharme L, Thérond P, Nigon F et al. (1999) Cholesteryl ester hydroperoxide lability is a key feature of the oxidative susceptibility of small, dense LDL. Arterioscler Thromb Vasc Biol 19:810-820

139. Goldberg IJ (2001) Diabetic dyslipidemia: causes and consequences. J Clin Endocrin Metab 86:965-971

140. Syvänne M, Ahola M, Lahdenperä S et al. (1995) High density lipoprotein subfractions in non-insulin-dependent diabetes mellitus and coronary artery disease. J Lipid Res 36:573-582

141. Pascot A, Lemieux I, Prud'homme D et al. (2001) Reduced HDL particle size as an additional feature of the atherogenic dyslipidemia of abdominal obesity. J Lipid Res 42:2007-2014
142. Syvänne M, Kahri J, Virtanen KS et al. (1995) HDLs containing apolipoproteins A-I and A-II (LpA-I:A-II) as markers of coronary artery disease in men with non-insulin-dependent diabetes mellitus. Circulation 92(3):364-370

143. Syvänne M, Castro G, Dengremont C et al. (1996) Cholesterol efflux from Fu5AH hepatoma cells induced by plasma of subjects with or without coronary artery disease and non-insulin-dependent diabetes: importance of LpA-I: A-II particles and phospholipid transfer protein. Atherosclerosis 127:245-253

144. Lamarche B, Rashid S, Lewis G F et al. (1999) HDL metabolism in hypertriglyceridemic states: an overview. Clin Chem Acta 286:145-161

145. Lamarche B, Uffelman KD, Carpentier A et al. (1999) Triglyceride enrichement of HDL enhances in vivo metabolic clearance of HDL apo A-I in healthy men. J Clin Invest 103:1191-1199

146. Rashid S, Barrett HR, Uffelman KD et al. (2002) Lipolytically modified triglyceride-enriched HDLs are rapidly cleared from the circulation. Arterioscler Thromb Vasc Biol 22:483-487

147. Golay A, Zech L, Shi A-Z et al. (1987) High density lipoprotein (HDL) metabolism in noninsulin-dependent diabetes mellitus: measurement of HDL turnover using tritiated HDL. J Clin Endocrinol Metab 65:512-518

148. Frénais R, Ouguerran K, Maugeais C et al. (1997) High density lipoprotein apolipoprotein AI kinetics in NIDDM: a stable isotype study. Diabetologia 40:578-583

149. Pietzsch J, Juselius U, Nitzsche S et al. (1998) In vivo evidence for increased apolipoprotein A-I catabolism in subjects with impaired glucose tolerance. Diabetes 47:1928-1934

150. Frénais R, Nazih H, Ouguerram K et al. (2001) In vivo evidence for the role of lipoprotein lipase activity in the regulation of apolipoprotein AI metabolism: a kinetic study in control subjects and patients with type 2 diabetes mellitus. J Clin Endocrinol Metab 86:1962-1967

151. Von Eckardstein A, Nofer J-R, Assmann G (2001) High density lipoproteins and arteriosclerosis, role of cholesterol efflux and reverse cholesterol transport. Arterioscler Thromb Vasc Biol 21:13-27

152. Tu A-Y, Albers JJ (2001) Glucose regulates the transcriptions of human genes relevant to HDL metabolism: Responsive elements for peroxisome proliferator-activated receptor are involved in the regulation of phospholipid transfer protein. Diabetes 50:1851-1856

153. Riemens SC, Tol A van, Sluiter WJ et al. (1999) Plasma phospholipid transfer protein activity is lowered by $24-\mathrm{h}$ insulin and acipimox administration. Diabetes 48:16311637

154. Miettinen H, Haffner SM, Lehto S et al. (1998) Impact of diabetes on mortality after the first myocardial infarction. Diabetes Care 21:69-75

155. Mukamai KJ, Maclure M, Nesto RW et al. (2001) Impact of diabetes on long-term survival after acute myocardial infarction. Diabetes Care 24:1422-1427

156. Haffner SM (2003) Management of dyslipidemia in adults with diabetes. Diabetes Care 26 [Suppl]:S83-S86

157. Pyörälä K, Pedersen TR, Kjekshus J et al. (1997) Cholesterol lowering with simvastatin improves prognosis of diabetic patients with coronary heart disease. Diabetes Care 20:614-621

158. Goldberg RB, Mellies MJ, Sacks FM et al. (1998) Cardiovascular events and their reduction with pravastatin in diabetic and glucose-intolerant myocardial infarction survivors with average cholesterol levels: subgroup analyses in the cholesterol and recurrent events (CARE) trial. Circulation 98:2513-2519 
159. Sacks FM, Tonkin AM, Craven T et al. (2002) Coronary heart disease in patients with with low LDL-cholesterol: benefit of pravastatin in diabetics and enhanced role for HDL-cholesterol and triglycerides as risk factors. Circulation 105:1424-1428

160. Heart Protection Study Collaborative Group (2002) $\mathrm{MRC} / \mathrm{BHF}$ heart production study of cholesterol lowering with simvastatin in 20536 high-risk individuals: a randomised placebo-controlled trial. Lancet 360:7-22

161. Armitage J, Collins R (2000) Need for large scale randomised evidence about lowering LDL cholesterol in people with diabetes mellitus: MRC/BHF heart protection study and other major trials. Heart 84:357-360

162. U.K. Prospective diabetes study group (1997) Plasma lipids and lipoproteins at diagnosis of NIDDM by age and sex. Diabetes Care 20:1683-1687

163. Diabetes atherosclerosis intervention study investigators (2001) Effect of fenofibrate on progression of coronaryartery disease in type 2 diabetes: the Diabetes Atherosclerosis intervention study, a randomised study. The Lancet 357:905-910

164. Gotto A, Farmer J A (2001) Pleiotropic effects of stations: do they mater? Curr Opin Lipidol 12:391-394

165. McFarlane S I, Muniyappa R, Francisco R et al. (2002) Pleiotropic effects of statins: lipid reduction and beyond. J Clin Endocrinol Metab 87(4):1451-1458

166. Liao JK (2002) Beyond lipid lowering: the role of statins in vascular protection. Int J Cardiol 86:5-18

167. Bloomfield Rubins H, Robins SJ, Collins D et al. (2002) Diabetes, Plasma insulin and cardiovascular disease. Arch Intern Med 162:2597-2604

168. Fruchart J-C, Duriwz P, Staels B (1999) Peroxisome proliferator-activated receptor-alpha activators regulate genes governing lipoprotein metabolism, vascular inflammation and atherosclerosis. Curr Opin Lipidol 10:245-257

169. Fruchart J-C, Staels B, Duriez P (2002) PPAR-alpha, lipoprotein metabolism, metabolic diseases and atherosclerosis. In: Fruchart J-C, Gotto AM Jr, Paoletti R, Staels B,
Catapano AL (eds) Peroxisome Proliferator Activated Receptors: from basic science to clinical applications, 18. Kluwer, Dordrecht, pp 63-79

170. Chinetti G, Lestavel S, Bocher V et al. (2001) PPARalpha and PPAR-gamma activators induce cholesterol removal from human macrophage foam cells through stimulation of the ABCA1 pathway. Nat Med 7:53-58

171. Singaraja RR, Fievet C, Castro G et al. (2002) Increased ABCA1 activity protects against atherosclerosis. J Clin Invest 110:35-42

172. Martens F, Visseren F, Lemay J et al. (2002) Metabolic and additional vascular effects of thiazolidinediones. Drugs 62:1463-1480

173. Duval C, Chinetti G, Trottein F et al. (2002) The role of PPARs in atherosclerosis. TRENDS in Molecular Medicine 8:422-430

174. Etgen GJ, Oldham BA, Johnson WT et al. (2002) A tailored therapy for the metabolic syndrome: the dual peroxisome proliferator-activated receptor- $\alpha / \gamma$ agonist LY465608 ameliorates insulin resistance and diabetic hyperglycemia while improving cardiovascular risk factors in preclinical models. Diabetes 51:1083-1087

175. Lindén D, Lindberg K, Oscarsson J et al. (2002) Influence of peroxisome proliferator-activated receptor $\alpha$ agonist on the intracellular turnover and secreation of apolipoprotein (Apo) B-100 and ApoB-48. J Biol Chem 277:23044-23053

176. Sugden MC, Bulmer K, Gibbons GF et al. (2002) Peroxisome-proliferator-activated receptor- $\alpha$ (PPAR $\alpha)$ deficiency leads to dysregulation of hepatic lipid and carbohydrate metabolism by fatty acids and insulin. Biochem $\mathrm{J}$ 364:361-368

177. Mayerson AB, Hundal RS, Dufour S et al. (2002) The effects of rosiglitazone on insulin sensitivity, lipolysis, and hepatic and skeletal muscle triglyceride content in patients with type 2 diabetes. Diabetes 51:797-802

178. Nichols AV, Krauss RM, Musliner TA (1986) Nondenaturing polyacrylamide gradient gel electrophoresis. Methods Enzymol 128:417-431 